\title{
RECONVERSION OF TRADITIONAL WATER EXTRACTION WINDMILLS IN MALLORCA TO PRODUCE ELECTRICAL POWER
}

\author{
José Pascual Tortella \\ Doctor Ingeniero Industrial \\ IDOM Ingeniería, Arquitectura y Consultoría \\ Av. Conde Sallent, $11-4^{\circ}$.- Palma de Mallorca (España) \\ Phone+34971425670 e-mail: jpascual@barcelona.idom.es
}

(paper 4292)

\begin{abstract}
:
Traditionally, windmills have been used in the agricultural area of Mallorca (Spain) and especially at Campos area, to extract water from wells and use it for watering.

During the Middle Ages the number of windmills grew. Most of them were for flour although some were also used for water. . From this moment on their growth was spectacular (in Palma there were 36 in 1872, 200 in 1891, 897 in 1951 and 1308 in 1958). There were easily over 3000 in all of Mallorca Island.

With the arrival of electrical mains and the explosion motor, motors that extract water replaced the windmills. Many windmills have disappeared, others are in precarious conditions.

One aspect that hasn't been dealt with until now is the technical analysis and the project of reconverting these slow rotational speed Machines moved by the energy of air in movement to take advantage of it in obtaining electrical power. The specific objectives that can be summed up as the following: . Reconvert and adapt a technology and means of taking advantage of the wind energy existing on this island, yet forgotten, and introducing the novelty of the production of electricity on a small scale in order to take full advantage of it, save and replace other sources of power in the agricultural sector (lighting, water extraction, watering, climatic adaptation of greenhouses, desalting brackish water, etc.) All of this improving the present visual and environmental impact, given the progressive state of abandonment and deterioration which the 3000 installations of this sort which are calculated to exist on the island of Mallorca and which are object of our attention.
\end{abstract}

\section{Introduction:}

Traditionally, windmills have been used in the Plá of Mallorca, in the agricultural area in the North of Mallorca and especially at Campos area, to extract water from wells and use it for watering. This is why we have chosen the name "Molcamp Project" for this attractive project.

Mallorca is a land of windmills. They are a usual sight in all the different municipalities, in the valleys, on a hill or in a village itself. The first graphic document of a windmill dates back to 1468, appearing in the Sant Jordi altarpiece by Pere Niçart, in the Diocesan Museum of Mallorca.

During the Middle Ages the number of windmills grew. Most of them were for flour although some were also used for water. All had a rotor and sails or fabric. Windmills started being fully used for water extraction in 1845 , by the Dutchman Paul Bouvy de Schorrenber. He had the intention of cutting down the drying out of the Plá of Sant Jordi. From this moment on their growth was

spectacular (in Palma there were 36 in 1872, 200 in 1891, 897 in 1951 and 1308 in 1958). There were easily over 2000 in all of Mallorca.

Aeolian power is an infinite and non-polluting source of energy. Its main drawbacks are its intermittence and low density.

With the arrival of electrical mains and the explosion motor, motors that extract water replaced the windmills. Gradually, these mechanisms and constructions deteriorated ending up creating the current depressing scenario. Many windmills have disappeared, others are in precarious conditions, and only a small percentage of them continue in acceptable conditions. They have either been rebuilt to continue extracting water from the subsoil or they have been restored purely aesthetically in order to improve the visual impact, which their beauty undoubtedly has on both foreigners and locals.

One aspect that hasn't been dealt with until now is the technical analysis and the project of reconverting these slow rotational speed Machines moved by the energy of air in movement to take advantage of it in obtaining electrical power.

\section{Environmental problem which the project refers to:}

The only autochthonous electrical power resources of the Balearic Islands are those that are renewable and those derived from the biomass. Among the conventional resources the only ones worth mentioning are the lignite deposits in Mallorca, which have been inactive since 1991 . Thus, $99 \%$ of the island's power production is obtained from importing power resources from outside, $45 \%$ of the total production corresponding to oil and its by-products and the remaining $55 \%$ to coal. 
For the production of electrical power $95 \%$ of the heavy oil products and the totality of coal produced on the islands.

The use of autochthonous power resources is very limited. In spite of this, the Balearic Islands are the first Autonomous Community regarding the surface of installed solar panels and the second in solar power in relation to the income per capita. The development of wind energy has been much less impressing, in spite of being traditionally the one and only renewable power used since the late eighteenth century until the late $50 \mathrm{~s}$ in this century.

Especially important are the development of pilot experiences and the demonstration effect, which can be achieved with the use of renewable power.

As was pointed out by the Worldwide Commission on the Environment and Development "the efficient use of electrical power must be the focus point of the electrical power policies in order to achieve a valid development". The efficient use of electrical power and the increasing importance that renewable sources must take on are the two main aspects of the Convention on Climatic Changes signed in Rio de Janeiro.

Making use of wind power has the great advantage of safeguarding the environment in a far superior manner than any of the conventional powers.

\section{Project Objectives}

The project being presented, in the case that it has a satisfactory result from the financial technical point of view that allows its relative generalisation to similar installations, is directed to achieve a series of very specific objectives that can be summed up as the following:

. Reconvert and adapt a technology and means of taking advantage of the wind energy existing on this island, yet forgotten, and introducing the novelty of the production of electricity on a small scale in order to take full advantage of it, save and replace other sources of power in the agricultural sector (lighting, water extraction, watering, climatic adaptation of greenhouses, desalting brackish water, etc.) All of this improving the present visual and environmental impact, given the progressive state of abandonment and deterioration which the 3000 installations of this sort which are calculated to exist on the island of Mallorca and which are object of our attention.

. Increase, to a certain extent (small yet worthwhile), the contribution of wind energy to the current electrical power offer on our islands.

. Develop this technological innovation as a production system of electrical power by using the traditional Mallorquín at water extraction windmills at Campos área, betwen Campos Village and the "Trenc" beach, as well as rationalise the use and consumption of the use and consumption of this power.

Promote among the different consumers affected directly and indirectly the rational and efficient use of electrical power, introducing the "expense" factor of electrical power in the conscience and mentality of the residents on our island, familiarising the consumer with this concept.

- Recuperation of a historical patrimony (until well into the nineteenth century windmills have been the only machines capable of providing mechanical energy for the service of industry or agriculture), reducing the currently negative visual, aesthetic and environmental impact of most of the windmills in the area and increasing their energetic and touristic interest; in the event that this investigation and development project is successful and its extrapolation to the rest of the areas of Mallorca.

The use of these aeolic devices to extract water and produce electrical power, it also has the doubtless interest of its energetic use in a merely environmental way, applied investigation technological development and demonstration. The rehabilitation of the windmills, which we have discussed and its use with this objective would also be an innovating practice in our country which is not very respectful of our industrial patrimony in general and what they represent, sometimes with a senseless eagerness to destroy and others due to the financial implication their upkeep entails.

It would be a good idea to stop and think that a technology which in our eyes may be old-fashioned, more akin to poets and painters than to engineers and in a way far from the productive world, was, for centuries an avant-garde industrial and agricultural activity, since they were the most powerful, fast and technically perfect machines of those days, paving the road for "mechanisation" and the current Aeolic technology.

This is the technical base that supports the presentation of this project: bring these aeolic devices closer to the present providing them with a current technology in order to carry out their role of making use of the wind for the production of electrical power, resolving the technical problems that are a part of it, at the same time as improving its visual, aesthetic and environmental impact in the area where they would be put to use.

\section{Technical Nature of the Project:}

There is nowhere on the Balearic Islands where the wind blows at more than $7 \mathrm{~m} / \mathrm{sec}$. On yearly average (measured at $10 \mathrm{~m}$ height). For this reason, and other technical ones (isolated electrical system and low potency regarding the demand) it isn't possible to replace other power sources with aeolic energy. It is only feasible as a complement to a conventional system or when a continuous use of the installation isn't necessary (water or power extraction or storage). 
Windmills make use of the wind's kinetic energy to convert it directly into mechanical energy. To extract water one adapts a piston pump and the intention behind the development of this project is to fit an electrical generator for the production of electricity, analysing the aeolic, mechanical, electrical and system control parameters which intervene, carrying out the complete project of the installation, analysing the possible alternative solutions, propose the system with most chance of success and, with it, implement to a 300 perfectly restored windmills at Campos area (Mallorca Island). All of this, to, finally, obtain the final conclusions and the "know-how" necessary for its eventual generalisation to 3000 traditional windmills existing at Mallorca Island.

The windmills we are discussing have a multiblade type (18 blades) harnessing surface of a $8 \mathrm{~m}$ diameter, slow speed (between 10 and 30 r.p.m.) which the wind blew on perpendicularly thanks to a rudder or tail, perpendicular and fixed to the before mentioned surface and parallel to the direction of the wind. With this a torque is generated in the axis which originates its turning movement, if this is superior to the resistant torque supplied by the piston pump which the system has fitted to it by means of a excentric mechanism and which is in charge of transforming the rotating movement of the rotor in a linear way (swinging).

Its optimum functioning is obtained for a characteristic speed $(\lambda)$ between 1 and 2 . The maximum obtainable power (theoretic) is deduced, approximately by the expression (Les Gourrieres, 1974):

$$
\mathrm{P}=0,15 \mathrm{D}^{2} \mathrm{~V}^{3}
$$

Being D the diameter of the rotor in meters; $\mathrm{V}$, the wind speed in $\mathrm{m} / \mathrm{s}$ and $\mathrm{P}$, the power obtained in watts.

These parts will be analysed briefly in order to provide a global vision of the existing technology and the technical improvements to be incorporated to achieve the goals that have been marked.

\section{a) Energy reception: Rotor}

The most characteristic element of the windmills are the antennas or blades which, attached to the bushing, constitute the rotor. There are two types, wood pieces and metalic blades.

The wood pieces rotor is unique to the windmills used for water extraction. Its structure is wood polygon of six, eight or twelve sectors, with a radius of between 4 and $6 \mathrm{~m}$.

The blade rotors are of a diameter of between 6 and 12 metres. Its structure is based on three steel circular hoops and circular section, concentric which axially support the blades (divided in six or twelve sectors) which converge in the centre of the bushing ("Star") where they meet; the blades are warped circular sectors. There are between 18 and 26 of them made of tin or galvanised iron plates, the first of which was installed in 1934.

In order to permit the adequate automatic orientation of the rotor in a perpendicular direction to the wind, the have a mobile tail. This structure can be oriented in the range of $360^{\circ}$ to allow catching the wind whatever direction it may blow in.

Its total longitude, including the support bar is around 1,2 times the radius of the rotor and its surface around $15 \%$ of the rotor surface.

\section{b) Movement transmission:}

The transmission system is in charge of transforming this rotating movement (up to a maximum of some 30 r.p.m.) in a linear swinging movement that sets a piston pump in motion. The excentric arm

system is the necessary and most simple transformation system. It appeared in the late Middle Ages and its use in water extraction windmills became popular.

It is based on the main axis having an excentricity (crankshaft) perpendicular to the axis itself, supported on both ends by a galvanised iron structure (wood in the older ones) in the shape of a "U" called "fork",

The crank is between 8 and 12 metres long, from the trunnion of the connecting rod to the articulated point which is joined to the rod of the pump, which it sets in motion.

\section{b) Work execution: Pump or "Cupet".}

The alternative movement pump used is an updated version of the Cresibi pump, used in the times of the Romans with human power. It consists of a cylinder ("Cupet") with two orifices provided with their corresponding clamp valves, through the interior of which moves a piston (Paneret o Pistó). When it rises it provokes a depression inside the cylinder, and which, being shut by a valve in the outgoing orifice it suctions the water from the well, filling it completely with the water that has been extracted. When the piston lowers, the valve that closes is the entry one, opening the outgoing one and thanks to the pressure from the piston's movement, the water that has been stored in the cylinder is impelled and expelled into the storage deposit (the maximum aspiration depth is $10.33 \mathrm{~m}$ ).

Originally the cylinder was made of pinewood although most of those nowadays are cast iron or bronze.

The technical characteristics of these pumps are the following: the cylinder has a diameter of between 0,15 and $0,60 \mathrm{~m}$. The piston stroke is of $0,40 \mathrm{~m}$ or $0,30 \mathrm{~m}$, giving the cylinder a volume of between $0,005 \mathrm{~m} 3$ (51) and $0,11 \mathrm{~m} 3(1101)$.

\section{d) Support System: Building and Tower}


A tower with a cylindrical or square base, of some 2 to 3 meters in diameter or on the side and $5 \mathrm{~m}$ tall supported the first windmills used for water extraction. In this case it is known as the "narrow tower".

Normally, these constructions have a square or circular base and are made of sandy stone typical of the island (marés) or of stone.

The whole group of transmission components are supported by a hollow metallic structure (made of wood in the older ones) "Box" ("Caixó") to allow the alternative movement of the tizo???, thus sustaining the whole thing. Moreover, this structural tower must have the possibility of turning on itself to permit the orientation of the blades in the wind. This is why it is imbedded in the supporting building itself with the hoop or the roller bearing which is resistant to axial efforts of a large interior diameter ( 30 to $40 \mathrm{~cm}$ ), and is supported by another as a base, known as "Grabaldina", which is in charge of holding the weight of the entire construction, keeping it straight.

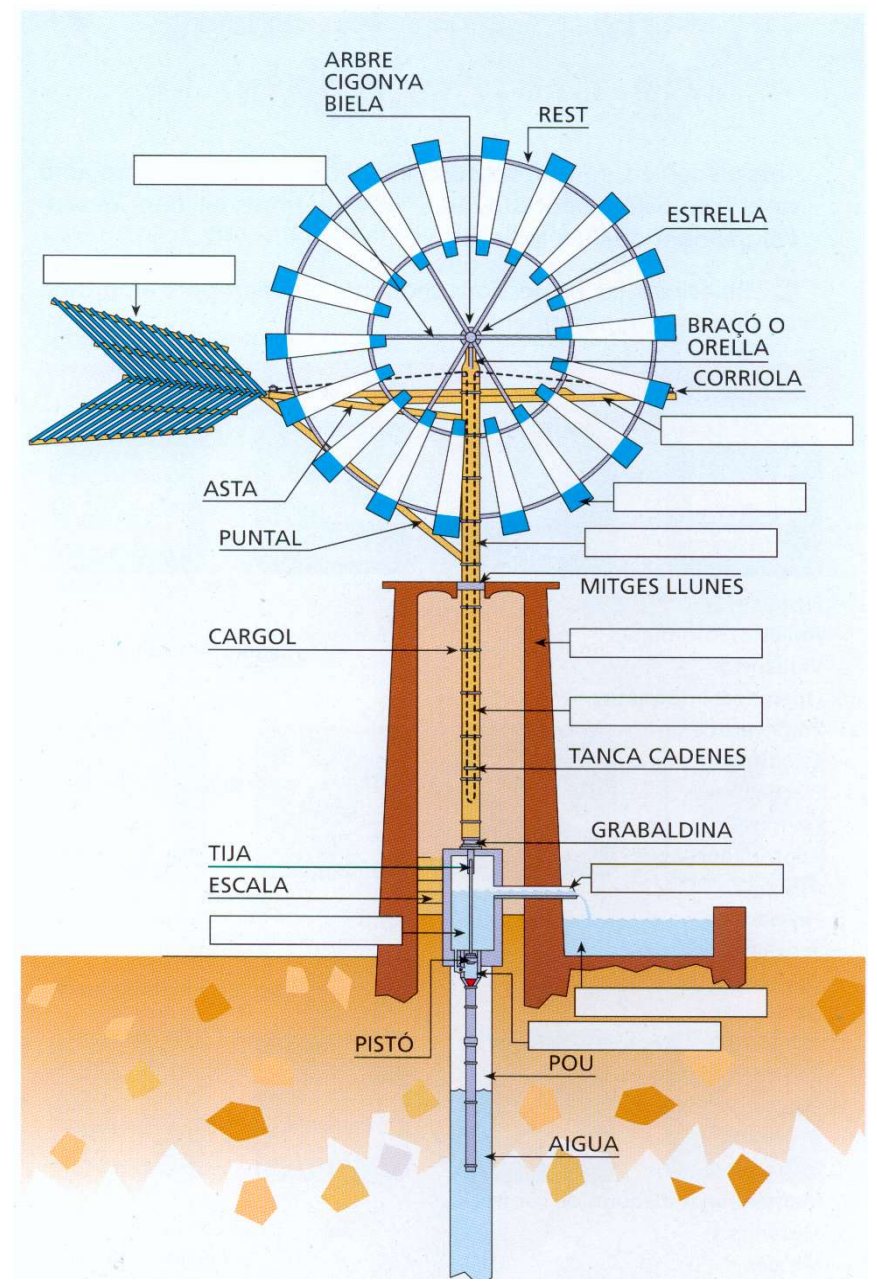

\section{Project dimensions}

Incorporating this system of electricity production to be developed and the restoration of the traditional windmills for water extraction located in the flat areas near the coast on the island of Mallorca could reach a considerable number, easily reaching 950 .
The dimensions of the project, if its advantages are proven and it was used in all these 950, would guarantee its results in other areas of Mallorca itself. It would also mobilise the infrastructure and create the minimum industrial network of mechanic workshops to make metallic parts, put them together and up-keep, which nowadays virtually doesn't exist or is in the process of disappearing.
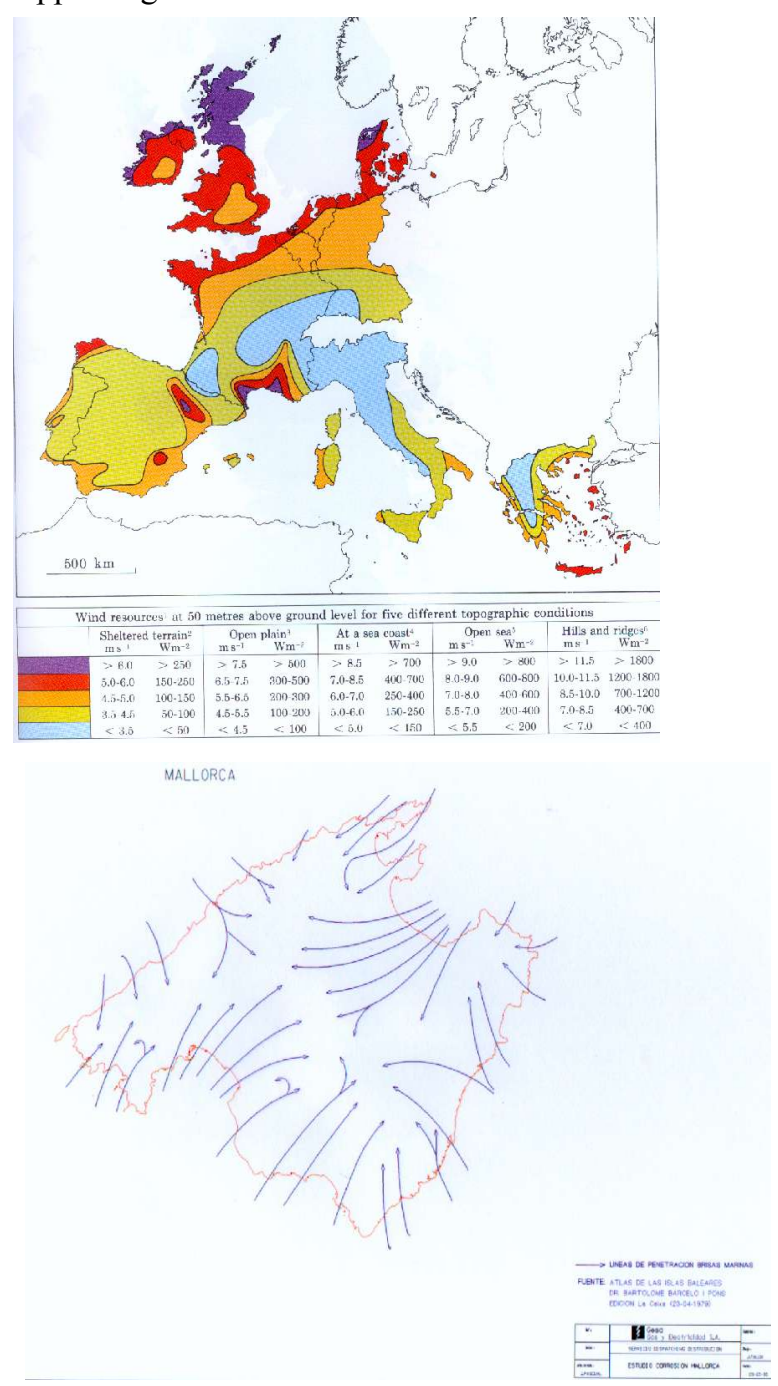

\section{Expected results}

Once the power curve which has been validated with difficult calculations and contrasting work with experimental results has been determined; it has been confronted with data concerning wind speed from different sources (National Meteorological Institute, European Wind Atlas, Aeolic Map of the Balearics, etc.)

The speed of the wind in the area where the windmills are located is characterised by breezes that are especially common during the hottest semester owing to the overheating of the land in respect to the sea (this wind is known as "Embat"). This guarantees the phenomenon will repeat, and thus the annual power needed will be known. 
The average annual speed is between 4 and $5 \mathrm{~m} / \mathrm{s}$, to which applying the distribution of probability of the density of the speed of wind of Weibull with a $\mathrm{K}$ of 2 which corresponds to a low variability:

In these conditions, the distribution of wind speeds conclude that between 19.000 and $25.000 \mathrm{~m} 3$ /year of water could be extracted per windmill per year, which means a savings of between 9.000 and 12.000

$\mathrm{kWh} /$ year/windmill.

If the number of windmills to be rebuilt rises to some 900, the mentioned quantities become some 22,5 million litres of water per year, which represents about 10 million $\mathrm{kWh}(10 \mathrm{GWh})$ of conventional power replaced per year. This energy is equivalent to $860 \mathrm{Tep} /$ year $(1 \mathrm{Tep}=0,086$ Mwh), which, in other types of fuels would come to:

-Coal:

-Solid residues:

-Agricultural fuel:

- Diesel oil:

The energy produced with these means could represent $0,043 \%$ of the total power consumed in the Balearics in $1996,1 \%$ of liquid petroleum gas distributed (99.816 Tep) and 4\% of the gas manufactures in the same region and year.

The installed power of windmills $(2.700 .000) \mathrm{w}$. Approx.) would represent some 70 times the fotovolcaica Power installed in the Balearics in 1996 and would equal the total installed of this sort since 1986.

CURVA DE PRODUCCIÓN ENERGÉTICAESTIMADA

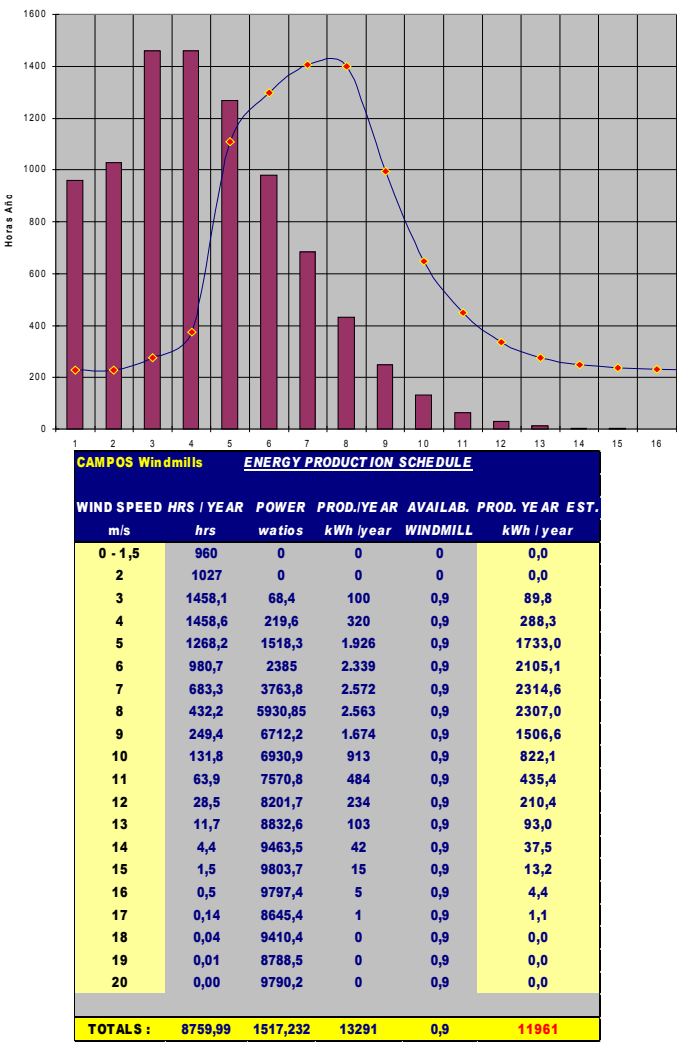

7. Viability and financial interest of the proposed technique:
It is fair to admit that the viability of this Project cannot be evaluated objectively as totally positive, if it is done from a purely energetic point of view, due to its lack of specific weight, however, this does not imply that these energy resources, quite considerable on this island, be ignored.

Thus, it is necessary to point out the demonstration character of this project, with its repercussion due to the possibility of it extending over a considerable, mainly rural, surface, with a great number of visitors. Its value as an example or testimony to great energy savings as well as the innovative aspect of the proposed technique, without spoiling the traditional aspect and function of Windmills, all this makes its viability possible, involving the industrial sector on a small scale, energy, agriculture and tourism with the absolutely necessary attention to the environment.

These reasonings, as well as the environmental benefits already mentioned compose a favourable and highly interesting scenario.

\section{Acknowledgement}

We aknowledge to the supporting Entities:

Ministry of Environment of Spain

Campos Municipality

Gesa-ENDESA

IDAE

Campos Agricol Cooperative

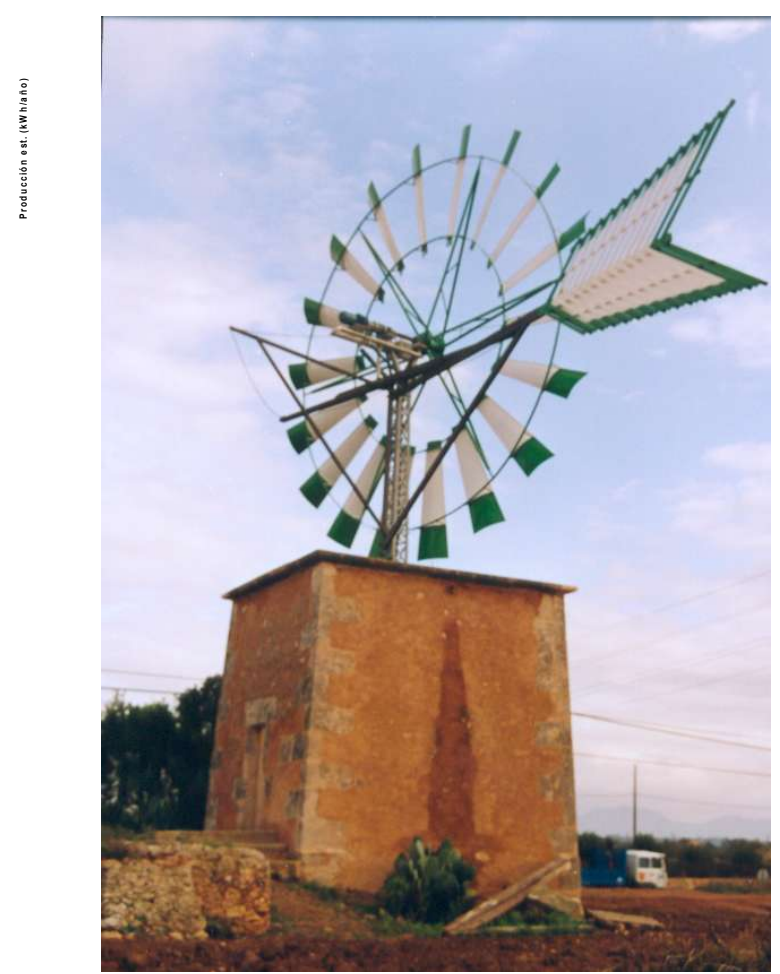

IDOM Engineering, Architecture and consultant is the enginnering that has been carried-out the project. 


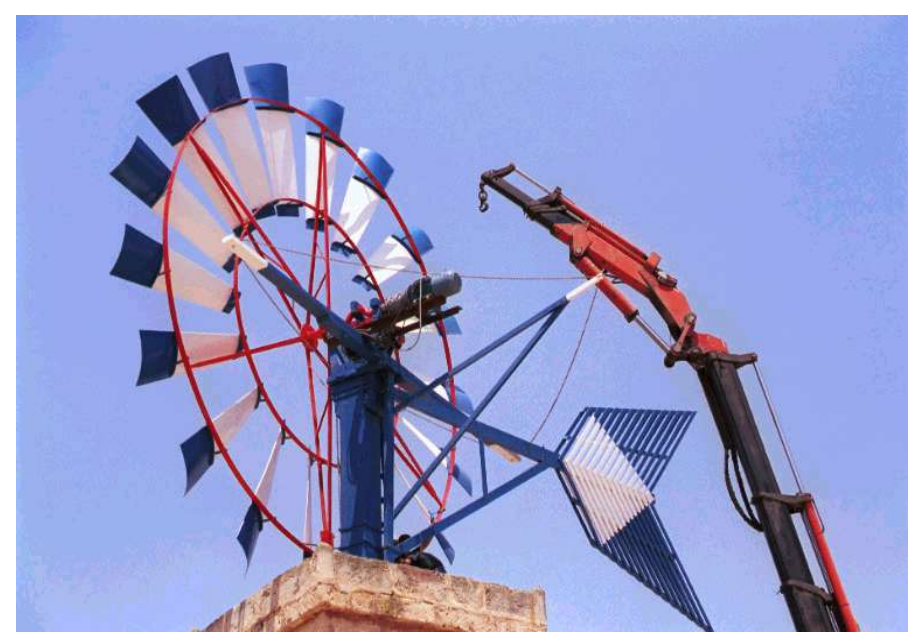

